\title{
Management of Urinary Retention in Patients with Benign Prostatic Obstruction: A Systematic Review and Meta-analysis
}

\author{
Markos Karavitakis ${ }^{a}$, Iason Kyriazis ${ }^{b}$, Muhammad Imran Omar ${ }^{c}$, Stavros Gravas ${ }^{d}$, \\ Jean-Nicolas Cornu ${ }^{e}$, Marcus J. Drake ${ }^{f}$, Mauro Gacci ${ }^{g}$, Christian Gratzke ${ }^{h}$, \\ Thomas R.W. Herrmann ${ }^{i, j}$, Stephan Madersbacher ${ }^{k}$, Malte Rieken ${ }^{l}$, Mark J. Speakman ${ }^{m}$, \\ Kari A.O. Tikkinen ${ }^{n}$, Yuhong Yuan ${ }^{\circ}$, Charalampos Mamoulakis ${ }^{p, *}$
}

${ }^{a}$ Center of Minimal Invasive Urology Athens Medical Center, Athens, Greece; ${ }^{\mathrm{b}}$ Department of Urology, University of Patras, Patras, Greece; ${ }^{\mathrm{C}}$ Academic Urology Unit, University of Aberdeen, Aberdeen, Scotland, UK; ${ }^{\mathrm{d}}$ Department of Urology, Faculty of Medicine, School of Health Sciences, University of Thessaly, Larissa, Greece; ${ }^{\mathrm{e}}$ Department of Urology, Charles-Nicolle University Hospital, Rouen Cedex, France; ${ }^{\mathrm{f}}$ Translational Health Sciences, Bristol Medical School, University of Bristol and Bristol Urological Institute, Bristol, UK; ${ }^{\mathrm{g}}$ Minimally Invasive and Robotic Surgery, and Kidney Transplantation, University of Florence AOUCCareggi Hospital, Florence, Italy; ${ }^{\mathrm{h}}$ Department of Urology, Albert-Ludwigs-University, Freiburg, Germany; ${ }^{\mathrm{i}}$ Urology Clinic, Spital Thurgau AG, Frauenfeld, Switzerland; ${ }^{j}$ Department of Urology and Urological Oncology, Hanover Medical School, Hanover, Germany; ${ }^{\mathrm{k}}$ Department of Urology, Kaiser-Franz-JosefSpital, Vienna, Austria; ${ }^{1}$ alta uro AG, Basel, Switzerland, University Basel, Basel, Switzerland; ${ }^{\mathrm{m}}$ Taunton E Somerset Hospital, Taunton, UK; ${ }^{\mathrm{n}}$ Departments of Urology and Public Health, University of Helsinki and Helsinki University Hospital, Helsinki, Finland; ${ }^{\circ}$ Division of Gastroenterology E' Cochrane UGPD Group, Department of Medicine, Health Sciences Centre, McMaster University, Hamilton, Canada; ${ }^{\mathrm{p}}$ Department of Urology, University General Hospital of Heraklion, University of Crete Medical School, Heraklion, Crete, Greece

\section{Article info}

Article history:

Accepted January 29, 2019

Associate Editor:

Maarten Albersen

Keywords:

Benign prostatic obstruction

Meta-analysis

Prostate

Randomized controlled trial

Treatment outcome

Urinary retention

\begin{abstract}
Context: Practice patterns for the management of urinary retention (UR) secondary to benign prostatic obstruction (BPO; UR/BPO) vary widely and remain unstandardized. Objective: To review the evidence for managing patients with UR/BPO with pharmacological and nonpharmacological treatments included in the European Association of Urology guidelines on non-neurogenic male lower urinary tract symptoms.

Evidence acquisition: Search was conducted up to April 22, 2018, using CENTRAL, MEDLINE, Embase, ClinicalTrials.gov, and World Health Organization International Clinical Trials Registry Platform. This systematic review included randomized controlled trials (RCTs) and prospective comparative studies. Methods as detailed in the Cochrane handbook were followed. Certainty of evidence ( $\mathrm{CoE}$ ) was assessed using the Grading of Recommendations Assessment, Development, and Evaluation (GRADE) approach.

Evidence synthesis: Literature search identified 2074 citations. Twenty-one studies were included (qualitative synthesis). The evidence for managing patients with UR/ BPO with pharmacological or nonpharmacological treatments is limited. CoE for most outcomes was low/very low. Only $\alpha 1$-blockers (alfuzosin and tamsulosin) have been evaluated in more than one RCT. Pooled results indicated that $\alpha 1$-blockers provided significantly higher rates of successful trial without catheter compared with placebo [alfuzosin: $322 / 540(60 \%)$ vs 156/400 (39\%) (odds ratio \{OR\} 2.28, 95\% confidence interval $\{\mathrm{CI}\} 1.55$ to 3.36 ; participants $=940$; studies $=7 ; I^{2}=41 \%$; low $\mathrm{CoE}$ ); tamsulosin: $75 / 158$ (47\%) vs $40 / 139$ (29\%) (OR 2.40, 95\% CI 1.29 to 4.45 ; participants = 297; studies $=3 ; I^{2}=30 \%$; low $\mathrm{CoE}$ )] with rare adverse events. Similar rates were achieved with tamsulosin or alfuzosin [51/87 (59\%) vs $45 / 84$ (54\%) (OR $1.28,95 \%$ CI 0.68 to 2.41 ;

* Corresponding author. Charalampos Mamoulakis; Department of Urology, University General Hospital of Heraklion, University of Crete Medical School, Heraklion, Crete, Greece. E-mail address: mamoulak@uoc.gr (C. Mamoulakis).
\end{abstract}

https://doi.org/10.1016/j.eururo.2019.01.046

0302-2838/@ 2019 European Association of Urology. Published by Elsevier B.V. All rights reserved. 
participants $=171$; studies $=2 ; I^{2}=0 \%$; very low CoE) $]$. Nonpharmacological treatments have been evaluated in RCTs/prospective comparative studies only sporadically.

Conclusions: There is some evidence that usage of $\alpha 1$-blockers (alfuzosin and tamsulosin) may improve resolution of UR/BPO. As most nonpharmacological treatments have not been evaluated in patients with UR/BPO, the evidence is inconclusive about their benefits and harms.

Patient summary: There is some evidence that alfuzosin and tamsulosin may increase the rates of successful trial without catheter, but little or no evidence on various nonpharmacological treatment options for managing patients with urinary retention secondary to benign prostatic obstruction.

(C) 2019 European Association of Urology. Published by Elsevier B.V. All rights reserved.

\section{Introduction}

Urinary retention (UR) is the inability of a patient to completely or partially empty the bladder by voluntary micturition. UR can be acute or chronic. Acute UR (AUR) is defined as a painful, palpable, or percussible bladder, when the patient is unable to pass any urine [1,2]. Chronic UR (CUR) is defined as a nonpainful bladder, which remains palpable or percussible after the patient has passed urine $[1,2]$. The term implies a significant postvoid residual urine volume (PVR); a minimum figure of $300 \mathrm{ml}$ has been mentioned [1,2]. Nevertheless, the exact definitions of AUR and CUR remain controversial [3]. The exact incidence of UR in the general population remains unclear, with various estimates suggested from 2.2 to 6.8 events/1000 patientyears $[4,5]$. Benign prostatic obstruction (BPO) is considered the most prevalent cause of UR in men [5].

Several $\alpha 1$-adrenoceptor antagonists ( $\alpha 1$-blockers) have been tested in patients with AUR to increase the rates of successful trial without catheter (TWOC), including alfuzosin [6-8], tamsulosin [6,9], and silodosin [10], most of which demonstrate a higher success rate than placebo. The alfuzosin in AUR (ALFAUR) study, the largest clinical trial to date, evaluated the role of alfuzosin $10 \mathrm{mg}$ once daily (OD) administrated 2-3 d before TWOC and showed that alfuzosin almost doubled the successful TWOC rate [11]. Since most patients having a successful TWOC have no AUR relapse in the short term, administration of an $\alpha 1$ blocker before catheter withdrawal is considered a valuable treatment [12]. It has been reported that $>80 \%$ of patients who did not receive any treatment after an AUR episode were submitted to surgery within $5 \mathrm{yr}$ [13]. As a result, pharmacological intervention should be considered not only an aid to increase the chance of successful TWOC, but also a mean to reduce AUR recurrence risk, which could lead to further interventions in the long term. Data from five studies, which evaluated the long-term use of $\alpha 1$-blockers, showed that patients receiving $\alpha 1$-blockers had a significantly lower risk of recurrent AUR [14]. The use of $5 \alpha$ reductase inhibitors (5ARIs) as a combination therapy with $\alpha 1$-blockers in AUR treatment is still controversial $[15,16]$. Urgent prostatic surgery is another therapeutic option for AUR, however with a higher risk of intra- and/or postoperative complications and mortality than elective surgery [17]. Therefore, elective surgery is the treatment of choice for most men who fail TWOC. Increased perioperative morbidity is also associated with the presence of an indwelling urinary catheter in cases operated after TWOC failure [18].

Management of UR secondary to BPO (UR/BPO) varies widely. Relevant systematic reviews (SRs) are scarce [1921]. The European Association of Urology (EAU) Nonneurogenic Male Lower Urinary Tract Symptoms (LUTS) Guidelines Panel acknowledges the current lack of high certainty of evidence ( $\mathrm{CoE}$ ) and the growing scientific base, and cites the need to understand more about management options. This SR is a product of this panel and compared the effectiveness of various treatment options currently available for patients with UR/BPO. The objective was to address the following questions:

1. What are the benefits of treatments for UR (AUR or CUR) in adults with BPO?

2. What are the harms of treatments for UR (AUR or CUR) in adults with BPO?

\section{Evidence acquisition}

Randomized controlled trials (RCTs), quasi-RCTs (QRCTs), and prospective comparative studies were included. Any other studies, such as noncomparative studies, retrospective studies, and case series, were excluded. Studies were included only if the following conditions were met:

1. UR (AUR or CUR)/BPO was addressed as a study outcome.

2. A subanalysis (or post hoc analysis) of participants presenting with UR (AUR or CUR)/BPO was reported.

3. Pharmacological treatment had been evaluated in an RCT or QRCT setting.

4. Nonpharmacological treatment had been evaluated in an $\mathrm{RCT}, \mathrm{QRCT}$, or prospective comparative study setting.

5. At least one of the primary or secondary outcomes of this SR was reported.

Adult men ( $\geq 18 \mathrm{yr}$ ) with UR (AUR or CUR defined as a persistently elevated PVR of $\geq 300 \mathrm{ml}$ ) secondary to BPO were included. Individuals with UR attributed to drug side effects, pharmacological/nonpharmacological procedures, suspected or confirmed urethral/bladder pathology (such as malignancy, urethral stricture, bladder neck contracture, bladder stones, neurogenic bladder, and infection/inflammation), or prostate cancer were excluded.

The following comparisons of intervention versus comparator were investigated: 


\section{Intervention:}

Any pharmacological or nonpharmacological treatment included in the EAU guidelines on non-neurogenic male LUTS (2018), as defined below:

1.

Pharmacological treatment (monotherapy or combination therapy): $\alpha 1$-blockers, 5ARIs, phosphodiesterase 5 inhibitors (PDE5Is), plant extracts (phytotherapy).

2. Nonpharmacological treatment: any kind of instrumental intervention (surgical treatment, such as transurethral resection of the prostate [TURP]), including suprapubic catheterization (SPC) or urethral catheterization irrespective of duration prior to TWOC.

3. Any combination of the above pharmacological and nonpharmacological treatments.

Comparator:

1. No treatment.

2. Placebo or sham treatment.

3. Any pharmacological or nonpharmacological treatment, as defined above (any comparison within intervention was accepted, such as comparison of different pharmacological treatments and/or comparison of different types of catheterization).

We performed a broad search of the Core Outcome Measures in Effectiveness Trials (COMET) database (http:// www.comet-initiative.org/) for a core outcome set (COS) using the term "urology" in the disease category. No directly applicable COS existed for the disease or treatments dealt in this SR. Therefore, the EAU Guidelines Panel reached consensus on what they regarded as most important outcomes for this condition. No patient advocates or other stakeholders were involved in the consensus process.

The primary benefit outcomes were the following:

1. Successful TWOC rate as defined by trials in each single study.

2. UR (AUR or CUR) recurrence rate following a successful TWOC.

The primary harm outcomes were as follows:

1. Harms of treatment for UR (AUR or CUR) including any adverse effects reported (such as death, pharmacological/nonpharmacological treatment complications). Surgical complications occurring up to 1 mo postoperatively, which were specifically graded according to the modified Clavien classification system [22,23].

The secondary outcomes included the following:

1. Maximum flow rate $\left(Q_{\max }\right)$, International Prostate Symptom Score (IPSS) questionnaire results (including quality of life [QoL] score), PVR; absolute values and changes from baseline at each follow-up time point.
2. Specific measures for evaluating nonpharmacological treatment (operation duration, bladder irrigation duration, postoperative catheterization, and hospitalization duration).

The Grading of Recommendations Assessment, Development, and Evaluation (GRADE) approach was used to assess CoE for each comparison [24]. CoE of outcomes considered critical/important in decision making from patients' perspective was rated based on study design, limitations in study design/execution (risk of bias [RoB]), inconsistency of results, indirectness of evidence, imprecision, and publication bias. Final decision on the selection of the outcomes to be rated was based on a consensus among the SR authors. We used the GRADEpro Guideline Development Tool to assess the CoE of the critical and important outcomes. Summary of findings (SoF) tables are available in the Supplementary material, and the following outcomes were chosen, listed according to priority:

1. Successful TWOC rate (at 1 mo after the intervention).

2. Modified Clavien classification system grade $\geq 3$ (at 1 mo after the intervention).

3. UR (AUR or CUR) necessitating additional pharmacological or nonpharmacological intervention rate following successful TWOC (at 12 mo after the intervention).

4. IPSS score (at 12 mo after the intervention).

5. QoL score (at 12 mo after the intervention).

The literature was systematically searched in accordance with the Preferred Reporting Items for Systematic Reviews and Meta-analyses (PRISMA) statement [25,26]. We followed the methodology as detailed in the Cochrane handbook for systematic reviews of interventions [27]. Search strategies are available in the Supplementary material.

The following electronic databases were searched up to April 22, 2018:

1. The Cochrane library databases (Cochrane Central Register of Controlled Trials [March 2018], Cochrane Database of Systematic Reviews [2005 to April 18, 2018]).

2. Medline (Ovid MEDLINE(R) In-Process \& Other NonIndexed Citations and Ovid MEDLINE(R) [1946 to April 2018]).

3. Embase (OvidSP [1974 to April 2018]).

Hand searches of the following trial registers/websites were also performed:

1. ClinicalTrials.gov (https://clinicaltrials.gov/).

2. World Health Organization International Clinical Trials Registry Platform (http://www.who.int/ictrp/en/).

3. For new(er) pharmacological compounds manufacturers' websites, Food and Drug Administration and European Medicines Agency websites were searched (no restriction on date of publication). 
Other potentially eligible studies were searched for using reference lists of included studies, other SRs, or health technology assessment reports. Search was supplemented by manually searching the reference list of the EAU guidelines on non-neurogenic male LUTS.

Two review authors (M.K. and I.K.) independently scanned the title or the abstract content, or both, of every record retrieved to determine which studies should be assessed further; extracted all data; and assessed RoB of each included study. Any disagreements were resolved through consensus or by consultation with a third author (C.M.). RoB in RCTs was assessed using the Cochrane "RoB" assessment tool $[27,28]$. "RoB" domains were judged as low, high, or unclear risk [27]. RoB in nonrandomized comparative studies was assessed using all the domains of Cochrane RoB tools [29]. In addition, a list of the six most important potential confounders for harm and benefit outcomes were developed a priori with clinical content experts (EAU Guidelines Panel on Nonneurogenic Male LUTS): (1) age, (2) severity of LUTS (IPSS score), (3) prostate volume, (4) active and previous medical treatment for BPO, (5) prior history of UR, and (6) history of prostatic infection. When at least two included trials were available for comparison of a given binary/dichotomous/ categorical benefit or harm outcome, data were expressed as odds ratio (OR) with $95 \%$ confidence interval (CI) and $p$ value where available. For continuous outcomes measured on the same scale, the intervention effect was estimated using mean difference $(95 \% \mathrm{CI})$. Meta-analysis was performed where more than one RCT reported the same outcome. In the event of substantial clinical/methodological heterogeneity, trial results were not reported as pooled effect estimate. Heterogeneity was identified by visually inspecting forest plots and by using a standard chi-square test with a significance level of $\alpha=0.1$. In view of the low power of this test, $I^{2}$ statistic was also considered, which quantifies inconsistency across trials to assess heterogeneity impact on the meta-analysis [30]. Heterogeneity was dealt as suggested in the Cochrane handbook for systematic reviews of interventions [27].

The protocol of the present SR was published on PROSPERO (Supplementary material).

\section{Evidence synthesis}

A total of 21 studies (18 RCTs [6-11,31-42] and three prospective comparative studies [43-45]) were included. Fig. 1 illustrates the literature flow. Table 1 presents baseline
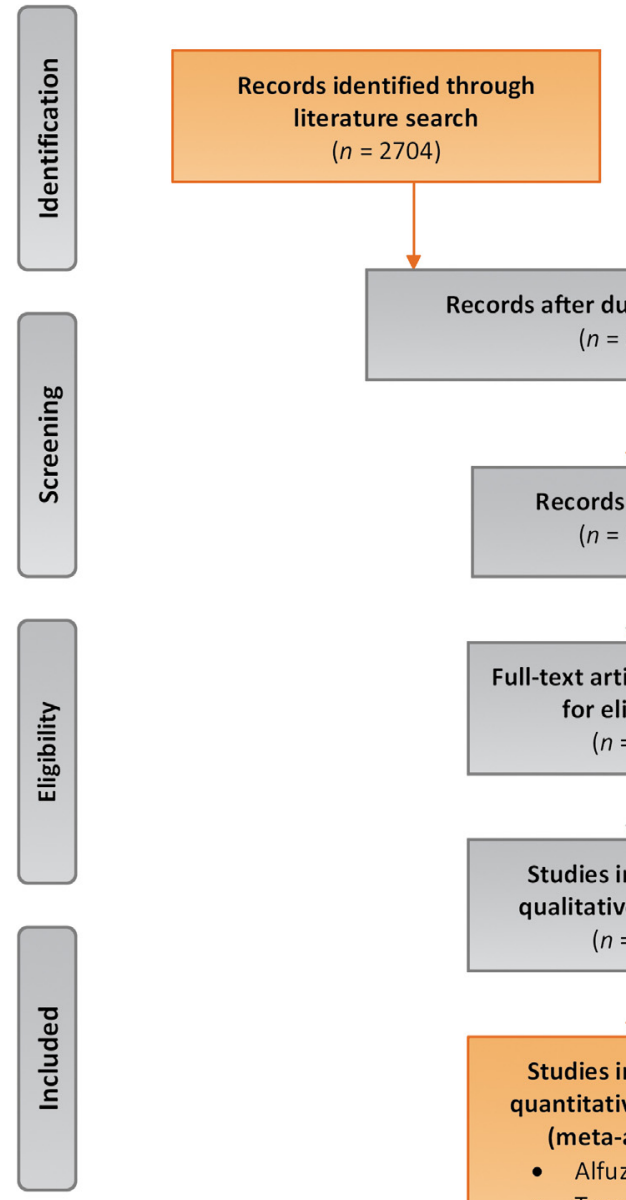

Additional records identified through other sources $(n=442)$ $(n=2704)$

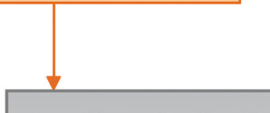

Records after duplicates removed $(n=3116)$

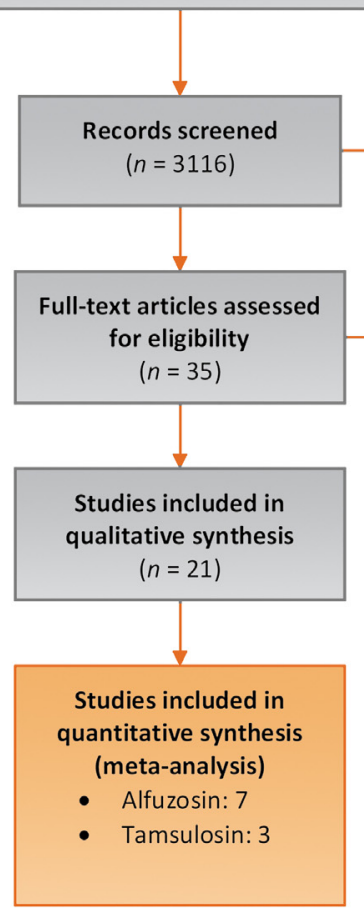

Fig. 1 - PRISMA flow diagram. Citations in conference abstract form and those written in non-English language were excluded. EAU = European Association of Urology; PRISMA = Preferred Reporting Items for Systematic Reviews and Meta-analyses; UR = urinary retention; BPO = benign prostatic obstruction. 
Table 1 - Baseline characteristics of included studies

\begin{tabular}{|c|c|c|c|c|c|c|c|c|c|c|}
\hline$\overline{\text { Study }}$ & Comparison & Design & $\begin{array}{l}\text { No. } \\
\text { of pts }\end{array}$ & $\begin{array}{c}\mathrm{FU} \\
(\mathrm{mo})\end{array}$ & Age (yr), mean (SD) & IPSS & $\begin{array}{l}\text { Prostate volume, } \\
\text { mean (SD) }\end{array}$ & $\begin{array}{c}\text { History } \\
\text { of medical } \\
\text { treatment }\end{array}$ & $\begin{array}{l}\text { History } \\
\text { of UR }\end{array}$ & $\begin{array}{l}\text { History } \\
\text { of prostatic } \\
\text { infection }\end{array}$ \\
\hline Agrawal (2009) [6] & $\begin{array}{l}\text { Alfuzosin } 10 \mathrm{mg} \text { vs tamsulosin } \\
0.4 \mathrm{mg} \text { vs placebo }\end{array}$ & RCT & 150 & $3 \mathrm{mo}$ & $\begin{array}{l}\text { Alfuzosin: } 69.4(8.8) \\
\text { tamsulosin: } 72.2(8.5)\end{array}$ & NR & NR & NR & 0 & 0 \\
\hline Al-Hashimi (2007) [31] & Alfuzosin $10 \mathrm{mg}$ vs placebo & RCT & 224 & $3 \mathrm{~d}$ & NR & NR & $65(100)$ & NR & 0 & NR \\
\hline \multirow[t]{2}{*}{ Hassan (2018) [32] } & $\begin{array}{l}\text { Tamsulosin } 0.4 \mathrm{mg} \text { OD for } 3 \mathrm{~d} \\
\text { vs tamsulosin } 0.4 \mathrm{mg} \text { OD for } \\
7 \mathrm{~d}\end{array}$ & RCT & 60 & 1.5 & $59.2(8.0)$ & $13.3(3.9)$ & $61.5(23.1)$ & 0 & 0 & NR \\
\hline & & & & & $60.5(9.7)$ & $13.2(3.3)$ & $57.9(25.0)$ & & & \\
\hline Kara (2014) [33] & $\begin{array}{l}\text { Tamsulosin } 0,4 \mathrm{mg} \text { vs } \\
\text { tamsulosin + alfuzosin } 10 \mathrm{mg} \\
\text { OD }\end{array}$ & RCT & 70 & 9 & 71.2 & NR & NR & NR & NR & NR \\
\hline Kumar (2013) [10] & Silodosin $8 \mathrm{mg}$ OD vs placebo & RCT & 60 & $3 \mathrm{~d}$ & $\begin{array}{l}\text { Silodosin: } 64.5 \text { (9.3); placebo: } \\
65.8 \text { (8.1) }\end{array}$ & $\begin{array}{l}\text { Silodosin: } 25.7 \\
\text { (2.5); placebo: } 26.6 \\
\text { (2.1) }\end{array}$ & $\begin{array}{l}\text { Silodosin: } 42.3(7.9) ; \\
\text { placebo: } 44.5(9.6)\end{array}$ & NR & NR & NR \\
\hline Lucas (2005) [9] & Tamsulosin $0.4 \mathrm{mg}$ vs placebo & RCT & 141 & 6.5 & 69.4 & NR & NR & NR & NR & NR \\
\hline Maldonado-Avila (2014) [34] & $\begin{array}{l}\text { Tamsulosin } 0.4 \mathrm{mg} \text { vs alfuzosin } \\
10 \mathrm{mg} \text { vs placebo }\end{array}$ & RCT & 90 & $5 \mathrm{~d}$ & $\begin{array}{l}\text { Tamsulosin: } 65.2(9.1) \text {; } \\
\text { alfuzosin: } 63.6(8.9)\end{array}$ & NR & NR & NR & NR & NR \\
\hline McNeil (1999) [7] & Alfuzosin $5 \mathrm{mg}$ bd vs placebo & RCT & 80 & Open & $\begin{array}{l}\text { Alfuzosin: } 67.7 \text { (13.6); placebo: } \\
72.7 \text { (8.33) }\end{array}$ & NR & NR & NR & NR & NR \\
\hline McNeill (2004) [11] & Alfuzosin $10 \mathrm{mg}$ OD vs placebo & RCT & 357 & 6 & $69.3(8.3)$ & NR & NR & NR & 0 & 10 \\
\hline Patil (2017) [35] & $\begin{array}{l}\text { Tamsulosin } 0.4 \mathrm{mg} \text { vs silodosin } \\
8 \mathrm{mg}\end{array}$ & RCT & 160 & 1 & $\begin{array}{l}\text { Tamsulosin: } 64.5(9.3) \text {; } \\
\text { silodosin: } 65.8(8.1)\end{array}$ & NR & $\begin{array}{l}\text { Tamsulosin: } 42.3(7.0) \text {; } \\
\text { silodosin: } 44.5 \text { (9.6) }\end{array}$ & NR & 0 & NR \\
\hline Prieto (2008) [36] & $\begin{array}{l}\text { Doxazosin } 4 \mathrm{mg} \text { vs no } \\
\text { medication }\end{array}$ & RCT & 46 & 24 & $74.4(8.4)$ & NR & $\begin{array}{l}\text { Doxazosin: } 61.2(30) \text {; } \\
\text { no medication: } 58.7 \\
(25)\end{array}$ & 0 & 0 & 0 \\
\hline Shah (2002) [8] & Alfuzosin $5 \mathrm{mg}$ bd vs placebo & RCT & 62 & 24 & Alfuzosin: 69.5; placebo: 67.7 & NR & NR & 0 & NR & 0 \\
\hline Sharifi (2014) [37] & $\begin{array}{l}\text { Tamsulosin } 0.4 \mathrm{mg}+\text { sildenafil } \\
50 \mathrm{mg} \text { vs tamsulosin + placebo }\end{array}$ & RCT & 101 & 3 & $\begin{array}{l}\text { Tamsulosin + sildenafil: } 59.6 \\
\text { (3.8); tamsulosin + placebo: } \\
60.6 \text { (4.1) }\end{array}$ & NR & $\begin{array}{l}\text { Tamsulosin + sildenafil: } \\
54.9 \text { (19.2); tamsulosin } \\
\text { + placebo: } 52.7 \text { (15.5) }\end{array}$ & 0 & 0 & 0 \\
\hline Tiong (2009) [38] & Alfuzosin $10 \mathrm{mg}$ vs placebo & RCT & 64 & $2 \mathrm{~d}$ & $\begin{array}{l}\text { Alfuzosin: } 72.5 \text { (10.3); placebo: } \\
71.9(9.4)\end{array}$ & $\begin{array}{l}\text { Alfuzosin: } 16.3 \\
\text { (8.7); placebo: } 18 \\
\text { (8.5) }\end{array}$ & NR & 0 & 0 & NR \\
\hline Ghalayini (2005) [39] & TURP vs CIC before TURP & RCT & 41 & 6 & TURP: 67 (8); CIC: 69 (7.3) & $\begin{array}{l}\text { TURP: } 25.8(4.2) \text {; } \\
\text { CIC: } 23.2(6.1)\end{array}$ & NR & NR & NR & NR \\
\hline Guazzoni (1993) [43] & $\begin{array}{l}\text { Prostatic spiral vs prostatic } \\
\text { stent }\end{array}$ & $\begin{array}{l}\text { Prospective } \\
\text { comparative }\end{array}$ & 38 & 12 & Spiral: 85; stent: 81 & NR & NR & NR & NR & NR \\
\hline Horgan (1992) [44] & Urethral catheterization vs SPC & $\begin{array}{l}\text { Prospective } \\
\text { comparative }\end{array}$ & 86 & 36 & NR & NR & NR & NR & NR & NR \\
\hline Mamoulakis (2013) [40,47] & M-TURP vs B-TURP & RCT & 113 & 36 & $\begin{array}{l}\text { M-TURP: } 70.4 \text { (9.5); B-TURP: } \\
72.2(8.6)\end{array}$ & NR & $\begin{array}{l}\text { M-TURP: } 69.5 \text { (37.2); B- } \\
\text { TURP: } 72.6 \text { (35.7) }\end{array}$ & 0 & NR & 0 \\
\hline Patel (2001) [45] & $\begin{array}{l}\text { CIC vs indwelling } \\
\text { catheterization }\end{array}$ & $\begin{array}{l}\text { Prospective } \\
\text { comparative }\end{array}$ & 50 & NR & $\begin{array}{l}\text { CIC: 69; Indwelling catheter: } \\
71\end{array}$ & NR & NR & NR & NR & NR \\
\hline Schelin (2006) [41] & TUMT vs TURP/enucleation & RCT & 120 & 6 & $\begin{array}{l}\text { TUMT: 73; TURP/enucleation: } \\
73\end{array}$ & NR & $\begin{array}{l}\text { TUMT: 71.6; TURP/ } \\
\text { enucleation: } 66.8\end{array}$ & NR & NR & NR \\
\hline Zhengyong (2014) [42] & BT vs no BT & RCT & 845 & & 66 & $\begin{array}{l}\text { BT: } 19 \text { (6.9); no BT: } \\
20 \text { (7.9) }\end{array}$ & $\begin{array}{l}\text { BT: } 52 \text { (12.4); No BT: } 53 \\
(12.7)\end{array}$ & NR & 0 & 0 \\
\hline
\end{tabular}


(A)

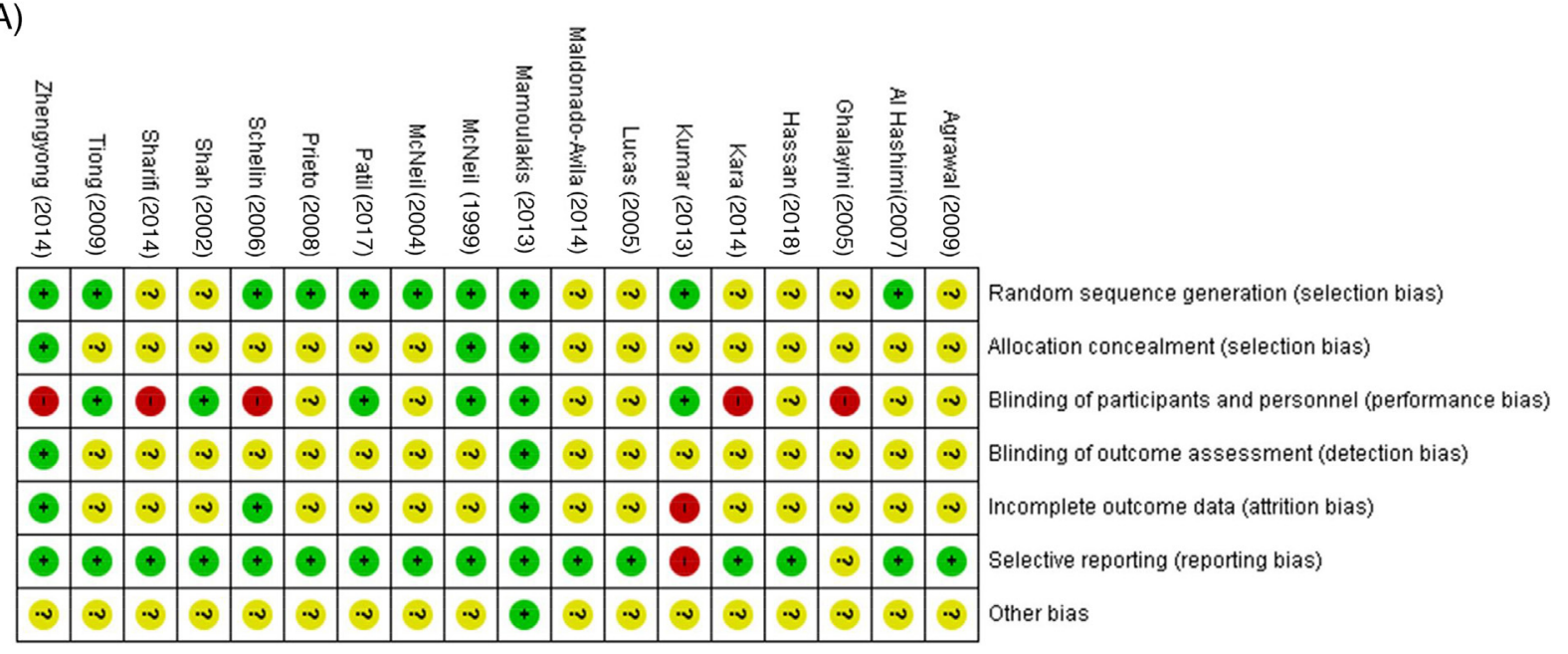

(B)

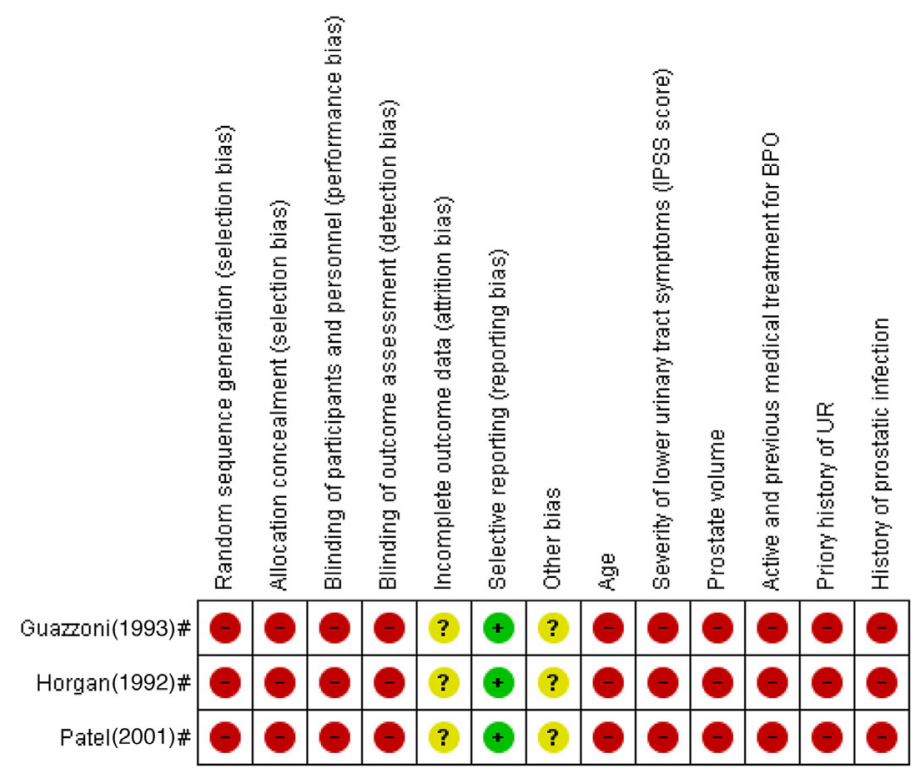

Fig. 2 - Risk of bias assessment of included studies (red: high risk of bias; yellow: unclear risk of bias; green: low risk of bias): (A) RCTs and (B) nonRCTs (prospective comparative studies). $\mathrm{BPO}=$ benign prostatic obstruction; IPSS = International Prostate Symptom Score; RCT = randomized controlled trial; $\mathrm{UR}=$ urinary retention.

characteristics of included studies. RoB assessment is illustrated in Fig. 2.

\subsection{Pharmacological treatments}

Among the pharmacological treatments included in the EAU guidelines on non-neurogenic male LUTS, only $\alpha 1$-blockers (alfuzosin, tamsulosin, silodosin, and doxazosin) and the PDE5I sildenafil have been evaluated for treating patients with UR/BPO in RCTs. No RCT addressing results on any other pharmacological treatment (monotherapy or combination therapy) included in the EAU guidelines on nonneurogenic male LUTS, such as 5ARIs (finasteride and dutasteride), was detected.

Alfuzosin was compared with placebo in seven RCTs [6$8,11,31,34,38]$. Pooled results indicated that alfuzosin provided significantly higher successful TWOC rates than placebo (322/540 [60\%] vs $156 / 400$ [39\%]; OR $2.28,95 \% \mathrm{CI}$ 1.55 to 3.36; participants $=940$; studies $=7 ; I^{2}=41 \%$; low CoE; Fig. 3). Adverse events, most commonly including dizziness, headache, and orthostatic hypotension, were generally rare, without any difference between arms. Tamsulosin was compared with placebo in three RCTs $[6,9,34]$. In two of them, patients were randomized to three arms (tamsulosin vs alfuzosin vs placebo) [6,34]. Pooled results indicated that tamsulosin provided significantly higher successful TWOC rates than placebo $(75 / 158$ [47\%] vs 40/139 [29\%]; OR 2.40, 95\% CI 1.29 to 4.45; participants $=297$; studies $=3 ; I^{2}=30 \%$; low CoE; Fig. 4) but similar rates to alfuzosin (51/87 [59\%] vs $45 / 84$ [54\%]; OR $1.28,95 \%$ CI 0.68 to 2.41 ; participants $=171$; studies $=2$; $I^{2}=0 \%$; very low $\mathrm{CoE}$ ). Tamsulosin was also compared with tamsulosin/alfuzosin combination in one RCT [33] and tamsulosin/sildenafil combination in another RCT [37]. No 


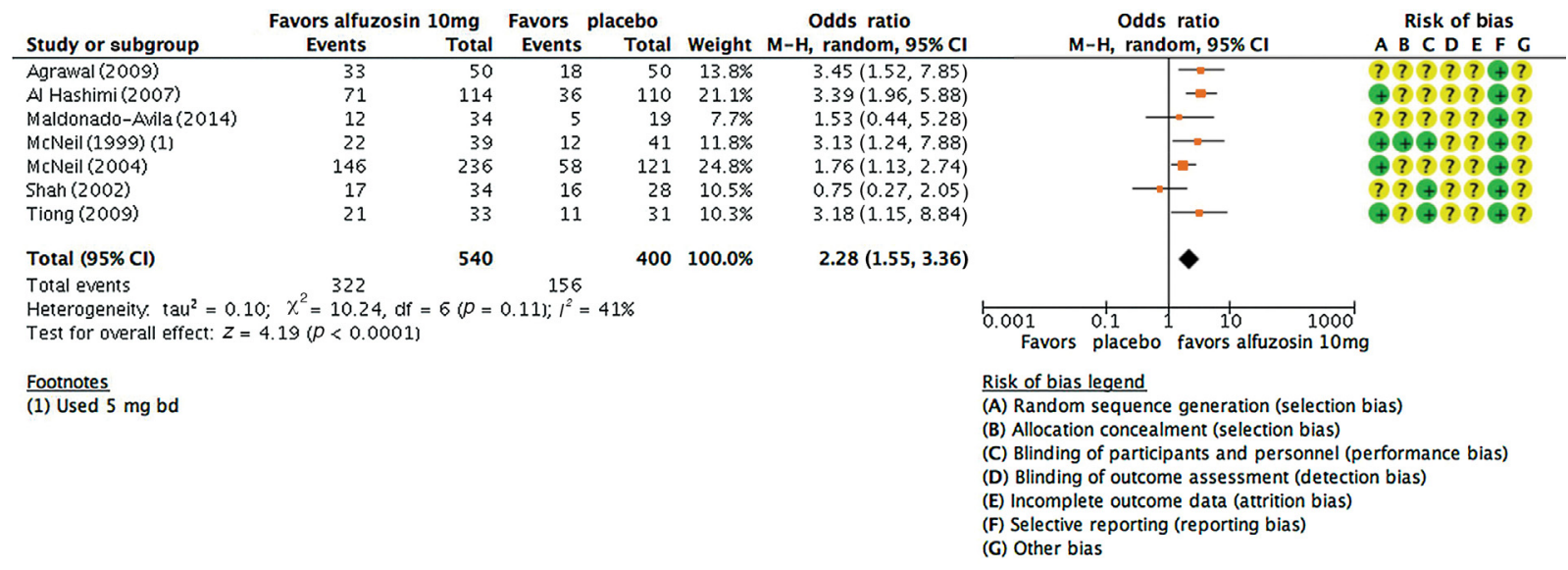

Fig. 3 - Alfuzosin versus placebo; successful TWOC rate at TWOC. $\mathrm{CI}=$ confidence interval; $\mathrm{M}-\mathrm{H}=\mathrm{Mantel}-\mathrm{Haenszel}$; TWOC = trial without catheter.

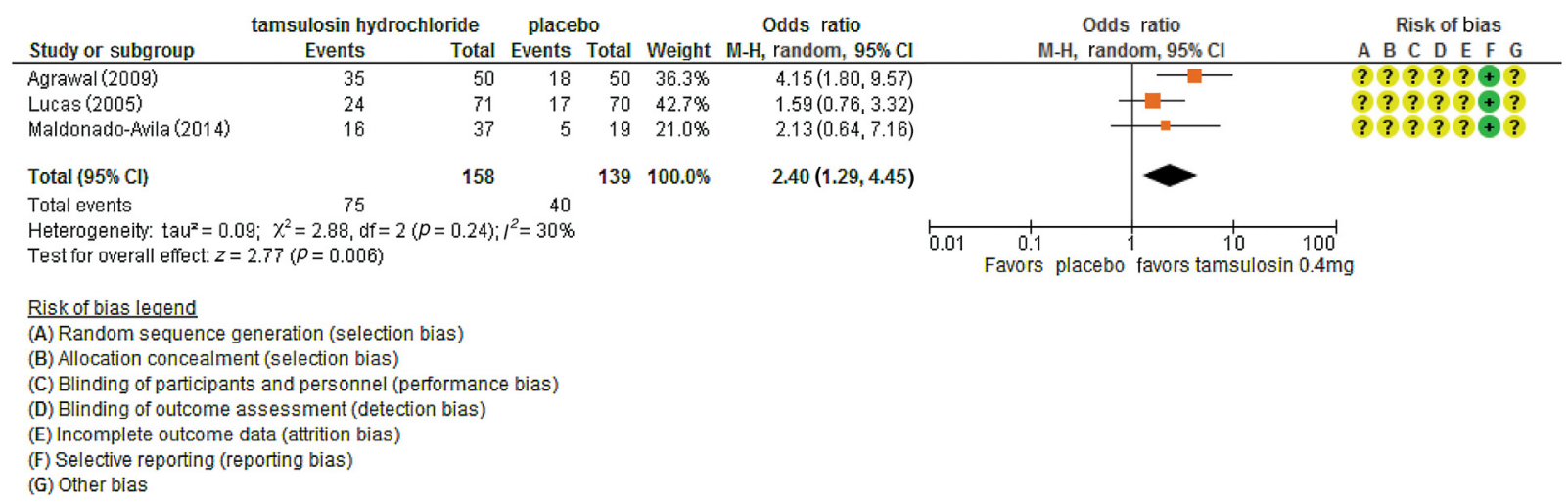

Fig. 4 - Tamsulosin versus placebo; successful TWOC rate at $\mathbf{T W O C}$. $\mathrm{CI}$ = confidence interval; $\mathrm{M}-\mathrm{H}=\mathrm{Mantel}-\mathrm{Haenszel}$; $\mathrm{TWOC}=$ trial without catheter.

difference between monotherapy and tamsulosin/alfuzosin combination was detected regarding successful TWOC rates: $11 / 35$ (31\%) versus 14/35 (40\%); OR 0.69, 95\% CI 0.26 to 1.84 ; participants $=70$; studies $=1$; very low CoE . Most common adverse events in the combination arm included dizziness, headache, and retrograde ejaculation, which were not significantly higher than those in the monotherapy arm [33]. The tamsulosin/sildenafil combination was also similar to monotherapy regarding successful TWOC rates: $41 / 50$ (82\%) versus 37/51 (73\%); OR 1.46, 95\% CI 0.66 to 3.25 ; participants $=101$; studies $=1$; very low CoE [37]. Three-day versus 7-d tamsulosin treatment for AUR was compared in one RCT [32]. No significant difference was observed in successful TWOC rates: $18 / 30$ (60\%) versus 21/ 30 (70\%); OR $0.64,95 \%$ CI 0.22 to 1.87 ; participants $=60$; studies $=1$; very low CoE. Silodosin was compared with placebo in one RCT, showing a significantly higher successful TWOC rate at $3 \mathrm{~d}$ : 23/30 (77\%) versus 11/30 (37\%); OR 5.68, 95\% CI 1.84 to 17.5 ; participants $=60$; studies $=1$; very low $\mathrm{CoE}[10]$. Silodosin was also compared with tamsulosin in one RCT showing no significant differences in successful TWOC rates: $48 / 80$ (60\%) vs 54/ 80 (68\%); OR $1.44,95 \%$ CI 0.76 to 2.71 ; participants $=160$; studies $=1$; very low $\mathrm{CoE}$ or complication rates between arms [35]. Doxazosin was compared with no medication in one RCT showing no difference in successful TWOC rates: $13 / 22$ (59\%) versus $13 / 24$ (54\%); OR $1.22,95 \%$ CI 0.38 to 3.93 ; participants $=46$; studies $=1$; very low CoE [36].

\subsection{Nonpharmacological treatments}

Very few nonpharmacological treatment options included in the EAU guidelines on the management of nonneurogenic male LUTS have been evaluated for managing patients with UR/BPO in RCTs/prospective comparative studies. None of them has been evaluated in more than one trial. An international multicenter RCT evaluated bipolar TURP (B-TURP) versus monopolar TURP (M-TURP) in 279 patients with BPO [40,46-48]. A subanalysis [46,47] and post hoc analysis (Supplementary Tables 1-3) on patients presenting with UR (B-TURP: $n=50$; M-TURP: $n=63$ ) revealed no difference between arms either for successful TWOC rates: 47/50 (94\%) vs 57/63 (90\%); OR 1.65, $95 \%$ CI 0.39 to 6.95; participants $=113$; studies $=1$; low $\mathrm{CoE}$ or for any of the outcomes of interest of this SR. In an RCT comparing transurethral microwave thermotherapy (TUMT) with TURP or open prostatectomy in patients with UR, no difference was detected in successful TWOC rates 
between arms: 48/61 (79\%) versus 52/59 (88\%); OR 0.58, $95 \%$ CI 0.22 to 1.52 ; participants $=120$; studies $=1$; very low CoE [41]. More complications were seen in TURP/ enucleation arm. In one RCT, the efficacy of bladder training before catheter removal was evaluated in patients with a first episode of AUR secondary to BPO randomized to pharmacological treatment (combination of tamsulosin $0.2 \mathrm{mg} /$ finasteride $5 \mathrm{mg}$ OD) with free catheter drainage for $7 \mathrm{~d}(n=405)$ or pharmacological treatment combined with bladder training $(n=440)$ prior to TWOC [42]. Similar successful TWOC rates $(190 / 405$ [47\%] vs $187 / 440$ [43\%]; OR $0.84,95 \%$ CI 0.64 to 1.10 ; participants $=840$; studies $=1$; moderate $\mathrm{CoE}$ ) and adverse event rates were observed in both arms. Transurethral catheterization versus SPC in patients with AUR was assessed in a prospective comparative study [44]. Thirty patients received transurethral catheterization and 56 patients received SPC (12F Cystofix). Patients were followed up for $3 \mathrm{yr}$. TWOC failure was observed in seven out of 11 patients (64\%) in the transurethral group versus seven out of 22 patients (32\%) in the SPC group. Complication rates were notably higher in the transurethral group (urinary tract infections [UTIs]: 12 out of 30 patients [40\%] vs 10 out of 56 patients [18\%], and urethral strictures: five out of 30 patients [17\%] vs none out of 56 patients [0.0\%]). Dislodgment was the only complication repeatedly associated with SPC: 13 patients (23\%; 11 of these patients needed catheter replacement) versus one patient (3.4\%), potentially necessitating a more secure form of catheter fixation such as a Foley catheter placement through a suprapubic introducer. Finally, our search criteria revealed an old study from 1993 comparing prostatic spiral (Uromed) with prostatic stent (Urolume) regarding effectiveness and complications [43]. Detailed results are available in the Supplementary material. SoF tables summarizing CoE assessment based on the GRADE approach are available in the Supplementary material.

\section{Discussion}

The evidence for managing patients with UR/BPO with pharmacological or nonpharmacological treatments is limited. CoE for most outcomes was low or very low. All selective $\alpha 1$ blockers (alfuzosin, tamsulosin, and silodosin) appear to be superior to placebo in terms of successful TWOC rates after a short period of catheterization [6,7,9-11,31,34,38]. In contrast, no benefit has been revealed with the use of the nonselective $\alpha 1$-blocker doxazosin, and addition of sildenafil to tamsulosin does not offer additional benefit compared with tamsulosin monotherapy. However, these studies are underpowered; CoE is very low and therefore no definite conclusions can be drawn for these comparisons [36,37]. Pooled results indicate that alfuzosin and tamsulosin monotherapy provide significantly higher successful TWOC rates than placebo with rare adverse events. Similar successful TWOC rates are achieved with alfuzosin or tamsulosin. Nonpharmacological treatments have been evaluated in RCTs/prospective comparative studies only sporadically.
B-TURP and TUMT have both been tested against M-TURP and found to have comparable efficacy/safety for the management of patients with UR according to the authors of these studies [40,41,46-48], but this conclusion should be interpreted with caution. SPC appears to safeguard against some of the potential complications of urethral catheterization such as UTI and urethral stenosis, allowing assessment of spontaneous voiding and avoiding recatheterization after a failed attempt [44]. Although it has been suggested that SPC might be associated with lower rates of UTI and urethral stricture formation, less patient discomfort, and easier management, a Cochrane SR failed to demonstrate a lower risk of symptomatic UTIs with use of SPC [49]. A 3-d rather than a 7-d period of catheterization after a first episode of AUR in addition to $\alpha 1$-blocker treatment should be preferred, since longer catheterization time increases complication rates without significantly increasing TWOC success [32]. A short period of intermittent self-catheterization might be beneficial to maximize recovery of bladder function before TURP and should be preferred to indwelling catheterization in case of delayed surgery, as it is associated with fewer infectious complications [32,36].

An SR on the management of AUR, including pharmacological and nonpharmacological treatment options, recommended the use of $\alpha 1$-blockers before TWOC, discouraging emergency operative management [21]. SPC over indwelling catheter use was debatable and catheterization duration was controversial, but $<3 \mathrm{~d}$ appeared to be a safe option in avoiding catheterization-related complications [21]. Although TURP remained the gold standard, there was emergence of newer operative management utilizing laser techniques [21]. Nevertheless, conclusions were limited due to low CoE [21].

In another SR, the effectiveness and comparative effectiveness of pharmacological and nonpharmacological treatments for CUR were evaluated [19]. A total of 11 studies (RCTs and prospective cohort studies) enrolling patients with CUR were included. Results were analyzed by etiology: obstructive, nonobstructive, and mixed populations/unknown causes. Only three studies addressed obstructive causes of CUR. Low-quality evidence suggested that TURP and TUMT achieved similar improvements in successful TWOC rates at 6 mo after treatment. Evidence was insufficient to draw conclusions regarding other outcomes. Evidence for other treatment comparisons for CUR from obstructive causes was insufficient to conclude that one treatment was more effective than the others. Evidence on harms was inconsistently reported across all interventions, and no differences were detected across treatment groups; however, studies were not adequately powered to detect differences in harms across groups. Further studies of patients with CUR are needed.

A Cochrane SR assessed the effectiveness of $\alpha 1$-blockers in successful resumption of micturition following removal of urethral catheter after an episode of AUR in men [20]. Nine RCTs were included. There was moderate CoE to suggest that successful TWOC rates favored $\alpha 1$-blockers over placebo. The incidence of recurrent AUR was lower in groups treated with 
$\alpha 1$-blockers. CoE was moderate favoring alfuzosin, tamsulosin, and silodosin, but not doxazosin. Of the trials mentioning adverse effects, there was not enough information to detect statistically significant differences between groups and $\mathrm{CoE}$ was low. Overall, adverse effect rates were low for both placebo and $\alpha 1$-blockers [20].

\subsection{Strengths and limitations of this $S R$}

The major strengths are as follows:

1. Performed a comprehensive literature search.

2. Adopted a robust/transparent methodological approach based on Cochrane handbook.

3. Assessed CoE with the GRADE approach.

The principal limitations are the following:

1. Although every effort was made following strict/specific trial exclusion criteria to exclusively include trials summarizing results from individuals with UR/BPO, the slight possibility of including few patients with neurological/bowel condition - or detrusor underactivity-associated UR or even few patients without (urodynamically proven) BPO cannot be completely ruled out since raw individual patient data were not accessible.

2. There was significant heterogeneity among identified studies.

3. Included studies had a relatively small number of participants, short follow-up, and methodological flaws with inadequate reporting. Although authors were contacted for information whenever needed, the majority did not reply. Therefore, following the guidelines of the Cochrane handbook, many RoB domains were judged as unclear, that is, providing insufficient information to permit judgment.

\subsection{Recommendations for future research}

Future studies should consider the following recommendations:

1. Several contemporary nonpharmacological treatment options included in the EAU guidelines on the management of non-neurogenic male LUTS were not assessed in this SR based on the inclusion criteria. For example, no comparative studies evaluating holmium, Greenlight, or thulium laser were detected. This represents a significant gap in the literature. Such a lack of evidence needs to be addressed by future studies since the subpopulation of UR patients is unique, harvesting specific perioperative risk factors.

2. Further studies on CUR as well as on 5ARIs after successful TWOC would be logical-as these, and not $\alpha 1$-blockers, have been shown to reduce AUR rates.

3. Previous UR is a well-established risk factor for ongoing AUR episodes. Older data indicated that only $16 \%$ of patients presenting with UR had remained catheter free for a period of $5 \mathrm{yr}$ [13]. According to the EAU guidelines on the management of non-neurogenic male LUTS, surgical treatment is usually required when patients have experienced, among others, recurrent/refractory UR or overflow incontinence (absolute operation indication, need for surgery) [50]. Nevertheless, future studies that will help reliably identify patients who could respond to prolonged medical treatment and who should be scheduled for prompt or elective surgery are deemed necessary.

4. Optimum treatment management for frail patients with significant comorbidities in the long term remains poorly documented, at least with respect to the studies directly comparing different treatment modalities (eg, surgery vs long-term catheterization). Future research should focus on this area.

5. The observed heterogeneity of TWOC success definitions among studies not only has an important impact on the assessment of treatment outcomes, but also renders adoption of a universally accepted definition of TWOC success necessary in future studies.

6. COS should be developed for UR/BPO, by following the COMET initiative.

7. Future studies should be adequately powered or should follow the principle/recommendation of Consolidated Standards of Reporting Trials (CONSORT) statement.

\section{Conclusions}

The evidence for managing patients with UR/BPO with pharmacological or nonpharmacological treatments is limited. CoE is generally low. There is some evidence that usage of $\alpha 1$-blockers (alfuzosin and tamsulosin) may improve resolution of UR/BPO. As most nonpharmacological treatments have not been evaluated in patients with UR/ $\mathrm{BPO}$, the evidence is inconclusive about their benefits and harms.

Author contributions: Charalampos Mamoulakis had full access to all the data in the study and takes responsibility for the integrity of the data and the accuracy of the data analysis.

Study concept and design: Omar, Gravas, Cornu, Drake, Gacci, Gratzke, Herrmann, Madersbacher, Rieken, Speakman, Tikkinen, Yuan, Mamoulakis.

Acquisition of data: Karavitakis, Kyriazis, Yuan.

Analysis and interpretation of data: Karavitakis, Kyriazis, Omar, Gravas, Mamoulakis.

Drafting of the manuscript: Karavitakis, Kyriazis, Mamoulakis.

Critical revision of the manuscript for important intellectual content: Omar, Gravas, Cornu, Drake, Gacci, Gratzke, Herrmann, Madersbacher, Rieken, Speakman, Tikkinen, Yuan, Mamoulakis.

Statistical analysis: Karavitakis, Omar, Mamoulakis.

Obtaining funding: None.

Administrative, technical, or material support: Yuan.

Supervision: Mamoulakis.

Other: None.

Financial disclosures: Charalampos Mamoulakis certifies that all conflicts of interest, including specific financial interests and relationships and affiliations relevant to the subject matter or materials discussed in the manuscript (eg, employment/affiliation, grants or funding, consultancies, honoraria, stock ownership or options, expert testimony, royalties, or patents filed, received, or pending), are the 
following: Marcus J. Drake has received speaker honoraria from Allergan, Astellas, and Ferring, and received grants and research support from Allergan, Astellas, and Ferring. Mauro Gacci is a company consultant for Bayer, Ibsa, GSK, Lilly, Pfizer, and Pierre Frabre; participates in trials for Bayer, Ibsa, and Lilly; and has received travel grants and research support from Bayer, GSK, and Lilly. Christian Gratzke is a company consultant for Astellas Pharma, Bayer, Dendreon, Lilly, Rottapharm-Madaus, and Recordati; has received speaker honoraria from AMS, Astellas Pharma, Pfizer, GSK, Steba, and Rottapharm-Madaus; and has received travel grants and research support from AMS, DFG, Bayer Healthcare Research, the EUSP, MSD, and Recordati. Stephan Madersbacher is a company consultant for Astellas, GSK, Lilly, and Takeda; and receives speaker honoraria from Astellas, Bohringer Ingelheim, GSK, Lilly, MSD, and Takeda. Jean-Nicolas Cornu is a company consultant for Cousin Biotech, AMS, Pfizer, Bouchara Recordati, and Coloplast; receives a company speaker honorarium from Astellas; has received grants/research supports from GSK and Servier; and received fellowship and travel grants from AMS, Bard, and EDAP-TMS. Mark Speakman is a company consultant for Astellas and GSK; receives company speaker honorarium from Astellas, Pfizer, GSK and Allergan; has participated in trials for Astellas, Allergan, GSK, and Abbot; and has been in receipt of grants/ research supports for GenProbe. Charalampos Mamoulakis is a company consultant for Astellas, GSK, and Teleflex; has received speaker honoraria from Elli Lilly; participates in trials for Astellas, Elli Lilly, Karl Storz Endoscope, and Medivation; and has received fellowships and travel grants from Ariti, Astellas, Boston Scientific, Cook Medical, GSK, Janssen, Karl Storz Endoscope, Porge-Coloplast, and Takeda. Stavros Gravas has received grants or research support from Pierre Fabre Medicament and GSK; has received travel grants from Angelini Pharma Hellas, Astellas, GSK, and Pierre Fabre Medicament; has received speaker honoraria from Angelini Pharma Hellas, Pierre Fabre Medicament, Lilly, and GSK; and is a consultant for Astellas, Pierre Fabre Medicament, and GSK. Thomas R.W. Herrmann declares receipt of honoraria, financial Support for attending symposia, financial support for educational programs, consultancy, advisory, and royalties from Karl Storz $\mathrm{GmBH}$; receipt of honoraria, financial support for attending symposia, financial support for educational programs, and consultancy from, and being in the advisory board of Boston Scientific AG; receipt of honoraria, financial support for attending symposia, and financial support for educational programs from LISA Laser OHG AG; and receipt of financial support for attending symposia from and being in the advisory board of Ipsen Pharma. Markos Karavitakis, Iason Kyriazis, Yuhong Yuan, Muhammad Imran Omar, Malte Rieken, and Kari A.O. Tikkinen have nothing to disclose.

Funding/Support and role of the sponsor: Kari A.O. Tikkinen was supported by the Academy of Finland (276046; 309387), Competitive Research Funding of the Helsinki and Uusimaa Hospital District (TYH2017114; TYH2018120), and Sigrid Jusélius Foundation.

\section{Appendix A. Supplementary data}

Supplementary data associated with this article can be found, in the online version, at https://doi.org/10.1016/j. eururo.2019.01.046.

\section{References}

[1] Abrams P, Cardozo L, Fall M, et al. The standardisation of terminology of lower urinary tract function: report from the Standardisation Sub-committee of the International Continence Society. Neurourol Urodyn 2002;21:167-78.
[2] Abrams P, Cardozo L, Fall M, et al. The standardisation of terminology in lower urinary tract function: report from the Standardisation Sub-Committee of the International Continence Society. Urology 2003;61:37-49.

[3] Kaplan SA, Wein AJ, Staskin DR, Roehrborn CG, Steers WD. Urinary retention and post-void residual urine in men: separating truth from tradition. J Urol 2008;180:47-54.

[4] Oelke M, Speakman MJ, Desgrandchamps F, Mamoulakis C. Acute urinary retention rates in the general male population and in adult men with lower urinary tract symptoms participating in pharmacotherapy trials: a literature review. Urology 2015;86:654-65.

[5] Verhamme KM, Dieleman JP, van Wijk MA, Bosch JL, Stricker BH, Sturkenboom MC. Low incidence of acute urinary retention in the general male population: the triumph project. Eur Urol 2005;47:494-8.

[6] Agrawal MS, Yadav A, Yadav H, Singh AK, Lavania P, Jaiman R. A prospective randomized study comparing alfuzosin and tamsulosin in the management of patients suffering from acute urinary retention caused by benign prostatic hyperplasia. Indian $\mathrm{J}$ Urol 2009;25:474-8.

[7] McNeill SA, Daruwala PD, Mitchell ID, Shearer MG, Hargreave TB. Sustained-release alfuzosin and trial without catheter after acute urinary retention: a prospective, placebo-controlled. BJU Int 1999;84:622-7.

[8] Shah T, Palit V, Biyani S, Elmasry Y, Puri R, Flannigan GM. Randomised, placebo controlled, double blind study of alfuzosin SR in patients undergoing trial without catheter following acute urinary retention. Eur Urol 2002;42:329-32.

[9] Lucas MG, Stephenson TP, Nargund V. Tamsulosin in the management of patients in acute urinary retention from benign prostatic hyperplasia. BJU Int 2005;95:354-7.

[10] Kumar S, Tiwari DP, Ganesamoni R, Singh SK. Prospective randomized placebo-controlled study to assess the safety and efficacy of silodosin in the management of acute urinary retention. Urology 2013;82:171-5.

[11] McNeill SA, Hargreave TB. Alfuzosin once daily facilitates return to voiding in patients in acute urinary retention. J Urol 2004; 171:2316-20.

[12] Taube M, Gajraj H. Trial without catheter following acute retention of urine. Br J Urol 1989;63:180-2.

[13] Breum L, Klarskov P, Munck LK, Nielsen TH, Nordestgaard AG. Significance of acute urinary retention due to intravesical obstruction. Scand J Urol Nephrol 1982;16:21-4.

[14] Michel MC, Goepel M. Lower urinary tract symptoms suggestive of benign prostatic obstruction-what's the long-term effectiveness of medical therapies? Eur Urol 2001;39(Suppl. 3):20-5.

[15] Kuiper JG, Bezemer ID, Driessen MT, et al. Rates of prostate surgery and acute urinary retention for benign prostatic hyperplasia in men treated with dutasteride or finasteride. BMC Urol 2016;16:53.

[16] Roehrborn CG, Siami P, Barkin J, et al. The effects of combination therapy with dutasteride and tamsulosin on clinical outcomes in men with symptomatic benign prostatic hyperplasia: 4-year results from the CombAT study. Eur Urol 2010;57:123-31.

[17] Pickard R, Emberton M, Neal DE. The management of men with acute urinary retention National Prostatectomy Audit Steering Group. Br J Urol 1998;81:712-20.

[18] Warren JW. Catheter-associated urinary tract infections. Infect Dis Clin North Am 1997;11:609-22.

[19] Brasure M, Fink HA, Risk M, et al. Chronic urinary retention: comparative effectiveness and harms of treatments. Rockville, MD: Agency for Healthcare Research and Quality; 2014.

[20] Fisher E, Subramonian K, Omar MI. The role of alpha blockers prior to removal of urethral catheter for acute urinary retention in men. Cochrane Database Syst Rev 2014;6:Cd006744. 
[21] Yoon PD, Chalasani V, Woo HH. Systematic review and meta-analysis on management of acute urinary retention. Prostate Cancer Prostat Dis 2015;18:297-302.

[22] Dindo D, Demartines N, Clavien PA. Classification of surgical complications: a new proposal with evaluation in a cohort of 6336 patients and results of a survey. Ann Surg 2004;240:205-13.

[23] Mamoulakis C, Efthimiou I, Kazoulis S, Christoulakis I, Sofras F. The modified Clavien classification system: a standardized platform for reporting complications in transurethral resection of the prostate. World J Urol 2011;29:205-10.

[24] Balshem H, Helfand M, Schunemann HJ, et al. GRADE guidelines: 3. Rating the quality of evidence. J Clin Epidemiol 2011;64:401-6.

[25] Moher DL, Liberty A, Tetzlaff J, Altman DG, PRISMA Group. Preferred reporting items for systematic reviews and meta-analyses: the PRISMA statement. PLoS Med 2009;6:e1000097.

[26] Liberati A, Altman DG, Tetzlaff J, et al. The PRISMA statement for reporting systematic reviews and meta-analyses of studies that evaluate health care interventions: explanation and elaboration. PLoS Med 2009;6:e1000100.

[27] Higgins JPT, Green S, editors. Cochrane handbook for systematic reviews of interventions, Version 5.1.0 (updated March 2011). The Cochrane. www.handbook.cochrane.org.

[28] Guyatt GH, Oxman AD, Kunz R, et al. GRADE guidelines: 7. Rating the quality of evidence-inconsistency. J Clin Epidemiol 2011;64:1294-302.

[29] Knoll T, Omar MI, Maclennan S, et al. Key steps in conducting systematic reviews for underpinning clinical practice guidelines: methodology of the European Association of Urology. Eur Urol 2018;73:290-300.

[30] Higgins JP, Thompson SG, Deeks JJ, Altman DG. Measuring inconsistency in meta-analyses. BMJ 2003;327:557-60.

[31] Al-Hashimi MMR. Alfuzosin $10 \mathrm{mg}$ once daily in the management of acute urinary retention of benign prostatic hyperplasia: a doubleblind, placebo-controlled study. Curr Urol 2007;1:28-34.

[32] Hassan S, El-Ebiary M, Mabrouk M. Early versus late trail of catheter removal in patients with urinary retention secondary to benign prostatic hyperplasia under tamsulosin treatment. Urol Sci 2018;29:288-92.

[33] Kara O, Yazici M. Is the double dose alpha-blocker treatment superior than the single dose in the management of patients suffering from acute urinary retention caused by benign prostatic hyperplasia? Urol J 2014;11:1673-7.

[34] Maldonado-Avila M, Manzanilla-Garcia HA, Sierra-Ramirez JA, et al. A comparative study on the use of tamsulosin versus alfuzosin in spontaneous micturition recovery after transurethral catheter removal in patients with benign prostatic growth. Int Urol Nephrol 2014;46:687-90.

[35] Patil SB, Ranka K, Kundargi VS, Guru N. Comparison of tamsulosin and silodosin in the management of acute urinary retention secondary to benign prostatic hyperplasia in patients planned for trial without catheter. A prospective randomized study. Cent Eur J Urol 2017;70:259-63.

[36] Prieto L, Romero J, Lopez C, Ortiz M, Pacheco JJ. Efficacy of doxazosin in the treatment of acute urinary retention due to benign prostate hyperplasia. Urol Int 2008;81:66-71.
[37] Sharifi SH, Mokarrar MH, Khaledi F, Yamini-Sharif R, Lashay A, Soltani $\mathrm{MH}$. Does sildenafil enhance the effect of tamsulosin in relieving acute urinary retention? Int Braz J Urol 2014;40:373-8.

[38] Tiong HY, Tibung MJ, Macalalag M, Li MK, Consigliere D. Alfuzosin $10 \mathrm{mg}$ once daily increases the chances of successful trial without catheter after acute urinary retention secondary to benign prostate hyperplasia. Urol Int 2009;83:44-8.

[39] Ghalayini IF, Al-Ghazo MA, Pickard RS. A prospective randomized trial comparing transurethral prostatic resection and clean intermittent self-catheterization in men with chronic urinary retention. BJU Int 2005;96:93-7.

[40] Mamoulakis C, Schulze M, Skolarikos A, et al. Midterm results from an international multicentre randomised controlled trial comparing bipolar with monopolar transurethral resection of the prostate. Eur Urol 2013;63:667-76.

[41] Schelin S, Geertsen U, Walter S, et al. Feedback microwave thermotherapy versus TURP/prostate enucleation surgery in patients with benign prostatic hyperplasia and persistent urinary retention: a prospective, randomized, controlled, multicenter study. Urology 2006;68:795-9.

[42] Zhengyong Y, Changxiao H, Shibing Y, Caiwen W. Randomized controlled trial on the efficacy of bladder training before removing the indwelling urinary catheter in patients with acute urinary retention associated with benign prostatic hyperplasia. Scand J Urol 2014;48:400-4.

[43] Guazzoni G, Montorsi F, Bergamaschi F, Consonni P, Bellinzoni P, Rigatti P. Prostatic spiral versus prostatic Urolume wallstent for urinary retention due to benign prostatic hyperplasia. A long-term comparative study. Eur Urol 1993;24:332-6.

[44] Horgan AF, Prasad B, Waldron DJ, O'Sullivan DC. Acute urinary retention. Comparison of suprapubic and urethral catheterisation. Br J Urol 1992;70:149-51.

[45] Patel MI, Watts W, Grant A. The optimal form of urinary drainage after acute retention of urine. BJU Int 2001;88:26-9.

[46] Mamoulakis C, Skolarikos A, Schulze M, et al. Results from an international multicentre double-blind randomized controlled trial on the perioperative efficacy and safety of bipolar vs monopolar transurethral resection of the prostate. BJU Int 2012;109:240-8.

[47] Mamoulakis C, Skolarikos A, Schulze M, et al. Bipolar vs monopolar transurethral resection of the prostate: evaluation of the impact on overall sexual function in an international randomized controlled trial setting. BJU Int 2013;112:109-20.

[48] Cetti RJ, Hicks JA, Venn SN, Carter PG, Britton JP. Results from an international multicentre double-blind randomized controlled trial on the perioperative efficacy and safety of bipolar vs monopolar transurethral resection of the prostate. BJU Int 2012;109:E38-40, [author reply].

[49] Kidd EA, Stewart F, Kassis NC, Hom E, Omar MI. Urethral (indwelling or intermittent) or suprapubic routes for short-term catheterisation in hospitalised adults. Cochrane Database Syst Rev 2015;12:CD004203.

[50] Gravas S, Cornu JN, Drake MJ, et al. Guidelines on the management of non-neurogenic male lower urinary tract symptoms (LUTS), incl. benign prostatic obstruction (BPO)Presented at the EAU Annual Congress Copenhagen 2018. Arnhem, The Netherlands: EAU Guidelines Office; 2018.978-94-92671-01-1 In: http://uroweb.org/ guideline/treatment-of-non-neurogenic-male-luts/ 